\title{
La producción de enfermedad en el paradigma de la salud del siglo XXI
}

\author{
Paula G. Rodríguez Zoya**
}

Recibido: 15 noviembre de 2012 - Aprobado: 23 de enero de 2013

\begin{abstract}
Resumen
Este trabajo pone en relación el imperativo de cuidado del cuerpo y la salud para alcanzar una salud perfecta y el fenómeno de expansión de la medicalización a través de la invención de enfermedades. La tesis central sostiene que la imbricación de ambos fenómenos constituye los fundamentos del paradigma sanitario que se arraiga en las sociedades occidentales del siglo XXI. La investigación problematiza la articulación de dichos fenómenos a partir de la circulación social de significaciones en torno a la salud, la enfermedad y el cuidado del cuerpo y la salud, producidas por discursos que atraviesan los procesos de medicalización de la condición humana y de la vida cotidiana. Se sistematizan los resultados del análisis de discurso de un corpus de cincuenta spots publicitarios referentes a productos médicos y cosméticos, emitidos en televisión abierta y cable en Argentina en 2009. El análisis del discurso publicitario de la industria farmacéutica permite reconstruir el sistema significante del imperativo de salud perfecta que opera como un dispositivo para la invención de enfermedades y la medicalización de la vida cotidiana.
\end{abstract}

Palabras clave: medicalización, salud perfecta, enfermedad, cuidado de la salud, paradigma sanitario

* Este trabajo forma parte de una investigación doctoral financiada por el Consejo Nacional de Investigaciones Científicas y Técnicas (CONICET) de Argentina, y ha sido desarrollado en el marco del proyecto de investigación de la Universidad de Buenos Aires, Biopolítica, medicalización e imperativo de la salud. Un análisis de las transformaciones de las nociones de cuerpo, vida y salud en la Argentina a partir de estudios de casos (2006-2009), dirigido por el Dr. Pablo Rodríguez y codirigido por la Dra. Flavia Costa.

** Licenciada en Ciencias de la Comunicación por la Universidad de Buenos Aires (UBA), becaria doctoral del Consejo de Investigaciones Científicas y Técnicas (CONICET) de Argentina y doctoranda en Ciencias Sociales de la UBA. Desarrolla su investigación en el Instituto de Investigaciones Gino Germani (IIGG) de la Facultad de Ciencias Sociales de la UBA. Se especializa en la investigación de procesos contemporáneos de medicalización, invención de enfermedades, construcción social del envejecimiento, imperativo de la salud perfecta, biopolítica y formas de gobierno sobre la vida, análisis de discurso sobre cuidado de la salud y del cuerpo, representaciones sociales sobre cuerpos, belleza y salud. Universidad de Buenos Aires (UBA) - Instituto de Investigaciones Gino Germani (IIGG). Consejo Nacional de Investigaciones Científicas y Técnicas (CONICET), Argentina. Email: paula.rzoya@gmail.com 


\title{
Disease Production in the Paradigm of XXI Century
}

\begin{abstract}
This research relates the need for a body care and health in order to achieve a perfect health and the expansion phenomenon of "medicalization" through the invention of diseases. The central thesis supports that the interdependence of both phenomena constitutes the basis of the sanitary paradigm which settles in XXI Western civilizations. This research make problematic the articulation of such phenomena from the social circulation of ideas, comments, thesis around health, disease, and body care and health which result from discourses of "medicalization" processes of human conditions and daily life. Results of discourse analysis of a corpus of fifty (50) advertising spots referring to medical and cosmetic products, published in an open television and Argentina cable in 2009 have been systematized. The analysis of the advertising discourse of pharmaceutical industry allows reconstructing the significance system of the need for a perfect health which operates as a device for the invention of diseases and "medicalization" of daily life.
\end{abstract}

Key words: "medicalization", perfect health, disease, health care, sanitary paradigm 


\section{Introducción}

La profusión de prácticas de cuidado del cuerpo y de la salud en las sociedades occidentales urbanas contemporáneas se expresa bajo la forma de un imperativo de salud perfecta. Esta tendencia a la búsqueda de salud perfecta mediante el cuidado corporal extremo es indisociable de la expansión de los procesos contemporáneos de medicalización (Costa y Rodríguez, 2010), aunque ambos fenómenos no siempre son estudiados de manera conjunta. La tesis central de este trabajo sostiene que la imbricación de salud perfecta y medicalización constituye los fundamentos del paradigma sanitario del siglo XXI. Esta investigación problematiza la articulación de dichos procesos con respecto a la configuración de marcas corporales y subjetivas en torno a la enfermedad, el control y la protección corporal. Específicamente, interesa analizar la producción de significaciones relativas al cuerpo, la salud y la enfermedad mediante discursos que atraviesan los procesos de medicalización de la condición humana y de la vida cotidiana.

El concepto de medicalización hace referencia a los procesos por los cuales la medicina moderna -sus prácticas, su discurso y su aparato tecnológico- invade un número creciente de esferas sociales y toma a su cargo como legítimos objetos de intervención médica, distintos tipos de problemáticas que con anterioridad no eran consideradas como tales (Conrad, 2007; Foucault, 1996b)'. El enfoque teórico de este trabajo rescata la perspectiva foucaultiana en la que el fenómeno de la medicalización es concebido como un "despegue médico y sanitario de las sociedades occidentales", pudiéndose identificar distintas formas de su manifestación en diversos momentos históricos como impulsos de una "curva" (Foucault, 1996a, pp. 85-86). La problemática de la medicalización en las sociedades contemporáneas como fenómeno de franca vigencia y expansión a nuevas esferas de la condición humana es estudiada en relación con las operaciones de invención de enfermedades (Blech, 2005; Moyniham, Heath y Henry, 2002; Smith, 2002). La revisión de la dinámica de estos fenómenos y su articulación con las demandas de mejoramiento de la salud y del cuerpo permitió proponer el constructo de paradigma de la salud del siglo XXI para hacer referencia a la orientación, matices y características que asume la "curva" de ese despegue médico y sanitario en las sociedades occidentales en el siglo XXI (Rodríguez Zoya, 2011).

Ahora bien, el abordaje de la dimensión corporal de un paradigma sanitario se hace ineludible en la medida en que la salud puede ser concebida como un estado que se predica de un cuerpo. Más aún, entendida como uno de los grandes nudos imaginarios de la época contemporánea, la denominada utopía de la salud perfecta supone la instalación previa de un nuevo sentido que permita su instauración social. Al respecto, Lucien Sfez (2008) sostiene que la fundación de ese sentido descansa en lo que él considera la base

1 Efectivamente, la expansión de la medicalización en la sociedad contemporánea incorpora nuevos problemas dentro de su accionar y crea nuevos mercados para el consumo (Cabral Barros, 2008). Los fenómenos de medicalización son estudiados en relación con la vida cotidiana (Moral Jiménez, 2008), la condición humana (Chodoff, 2002), la maternidad (Montse, 1991), el cuerpo de la mujer (Arroba, 2003), las patologías mentales (Conrad, 1982), la infancia (Muel, 1991), el uso de drogas (Epele, 2010), la alimentación (GarcíaArnaiz, 2007), la belleza (Díaz Rojo, 2002), el envejecimiento (Salvarezza, 2001), etcétera. 
material más extrema posible: el cuerpo. Siguiendo la huella trazada por Sfez, el cuerpo no solo es condición de la fundación del sentido, sino que, además, es garantía de una vida de bienestar desembarazada de las enfermedades. Claro está que la condición para que el cuerpo actúe como esta garantía es que goce de buena salud, y de allí puede comprenderse que la búsqueda de una salud perfecta asuma carácter de obsesión o de imperativo (Lupton, 1997).

Por otra parte, al tematizar las dimensiones, características y fundamentos de un paradigma sanitario, corresponde tratar propiamente el nivel de la salud y la concepción dada a su cuidado. Al respecto, en la utopía de la salud perfecta tematizada por Sfez, "la nueva moral de lo cotidiano pasa por el control del cuerpo" (2008, p. 329). Esta utopía pertenece a las utopías tecnológicas del siglo XXI, diferenciada de utopías sociales precedentes en tanto el enemigo que se busca combatir "no está más afuera sino dentro" (Sfez, 2008, p. 38)2. Frente a ese enemigo interno que Sfez llama a veces "el diablo", "lo otro", "el peligro", "lo secreto" o "lo oscuro", la utopía de la Gran Salud aspira a "la transparencia del cuerpo individual" para poder vigilar y controlar todo (Sfez, 2008, p. 333 el subrayado es mío).

En este marco, los objetivos que se propone este trabajo consisten en (1) reconocer las concepciones de cuerpo que pueden ser rastreadas como fundamentos teóricoepistemológicos de la dimensión corporal del paradigma de la salud del siglo XXI; (2) identificar las operaciones discursivas y significaciones en torno a la noción de cuerpo y control corporal producidas por el discurso publicitario de la industria farmacéutica, por constituir núcleos de sentido de la utopía de la salud perfecta; y (3) comprender los fundamentos de la dimensión corporal del paradigma de la salud del siglo XXI a partir de las regularidades significantes del discurso publicitario de la industria farmacéutica y de la concepción teórico-epistemológica de cuerpo que sustenta los fenómenos de medicalización y salud perfecta.

A continuación se exponen las cuestiones referentes a la metodología empleada en la investigación, atendiendo a la descripción del material empírico analizado y los criterios diseñados para la composición de la muestra. Luego tiene lugar una sección dedicada al desarrollo teórico en relación con la concepción de cuerpo en la que se fundamenta el complejo de la salud perfecta y los procesos de medicalización. Posteriormente, se sistematizan los resultados del proceso de análisis organizados en cuatro grandes núcleos semánticos. Finalmente, se desarrollan las principales conclusiones de la investigación en lo atinente al problema de las representaciones de las prácticas de cuidado y control corporal en la dinámica salud / enfermedad del paradigma de la salud del siglo XXI.

2 En relación con esta afirmación es oportuno señalar que Paul Valery, a quien se volverá en notas ulteriores, postula que el que él denomina "Mi-Cuerpo" es el cuerpo considerado como objeto de pertenencia, "esta cosa tan mía, y sin embargo, tan misteriosamente y, a veces, finamente siempre, nuestro más temible antagonista, es la más instante, la más constante y la más variable de las cosas; porque toda constancia y toda variación le pertenecen" (Valery, 1998, p. 86 el subrayado es mío). 


\section{Metodología y corpus de análisis}

El enfoque metodológico asumido en este trabajo es de tipo cualitativo y tiene la finalidad de comprender la producción de significaciones asociadas a las nociones de cuerpo, salud y enfermedad en el discurso de la industria farmacéutica en publicidades televisivas de productos farmacéuticos y cosméticos de venta libre. Esta delimitación empírica del objeto de estudio obedece a haber considerado que la industria farmacéutica se erige en un actor estratégico en la trama de los procesos de medicalización. Asimismo, el discurso publicitario televisivo relativo a productos de consumo masivo ha sido escogido por ser una de las formas discursivas contemporáneas de mayor alcance de neta orientación persuasiva; y por ello, propicio para el análisis de la producción significante en relación con el cuidado personal del cuerpo y la salud.

La estrategia metodológica radica en el análisis del discurso publicitario de la industria farmacéutica con la finalidad de hallar las significaciones que constituyen el núcleo de sentido de la utopía de la salud perfecta, a través de las operaciones discursivas para la invención de enfermedades. Los criterios de muestreo cualitativo consistieron en la selección de spots publicitarios que respondieran a las cinco variantes del denominado mecanismo de invención de enfermedades a partir de procesos de la vida (primera variante), problemas personales o sociales (segunda variante), factores de riesgo (tercera variante), síntomas poco frecuentes (cuarta variante) y síntomas leves (quinta variante), por las que opera la extensión de los procesos de medicalización (Blech, 2005; Rodríguez Díaz, 2008). Otro criterio de muestreo empleado en la construcción del corpus consistió en que el discurso de los spots permitiera identificar significaciones vinculadas a la salud, la enfermedad, la tecnología médica y el cuidado y control corporal, como dimensiones presentes en el imperativo de salud perfecta. En tal sentido, los principales aspectos teóricos de los fenómenos de medicalización y de salud perfecta han sido los criterios metodológicos para la construcción del diseño muestral. De acuerdo con estos lineamientos metodológicos se construyó una base de publicidades integrada por 325 spots referentes a medicamentos, cosméticos, bebidas, alimentos, suplementos dietarios y productos de tecnología médica, en soporte gráfico, radial y televisivo, emitidos en Argentina durante el período 2008-2010. Se emplearon los criterios de muestreo establecidos para la segmentar la base de publicidades y construir un corpus de análisis compuesto por cincuenta spots publicitarios emitidos por televisión abierta y cable en Argentina durante 2009.

La estrategia de análisis cualitativo consistió en el análisis de discurso publicitario efectuado desde la perspectiva de la primacía del orden significante (Lacan, 2003) y la producción de significación según las lógicas de la diferencia y la equivalencia (Laclau y Mouffe, 1987). En la sección correspondiente a los resultados de la investigación, se sistematizan figuras y núcleos semánticos conceptualizados a partir del análisis empírico del corpus de publicidades.

\section{La dimensión corporal del Paradigma de la Salud del siglo XXI}

El abordaje de la dimensión corporal constituye un eje central en la problematización de un paradigma de la salud. En el marco de los procesos de medicalización y el imperativo 
de salud perfecta, la reflexión teórica sobre el cuerpo no debe soslayar que la salud que se predica del mismo es adjetivada como "perfecta". La perfección -o, debería decirse mejor, la perfectibilidad - predicada respecto del cuerpo y la salud puede encontrar diversos tipos de fuente. Definitivamente, no es por obra de la gracia divina, acción de magia o alquimia alguna que el cuerpo al que alude Sfez aspire a un estado de salud perfecta. El "cuerpo trasplantado, restaurado, sometido a transformaciones genéticas es el fundamento último de lo real: ese real de inmortalidad y perfección de los seres naturales-artificiales" (Sfez, 2008, p. 330). La intervención médica, quirúrgica, plástica o genética -siempre tecnológicadel cuerpo es el medio para que este alcance el grado de perfección buscado. Claramente, el modo de concebir al cuerpo no fue históricamente el mismo: la dimensión corporal está atravesada por otra de carácter histórico-cultural. En este sentido, corresponde reparar en la relevancia de los procesos de individuación desarrollados cuando la Modernidad comenzaba a adquirir forma.

Hasta el siglo XV el cuerpo es la esencia del hombre y no se distinguen el uno del otro. El hombre tampoco se distingue de la trama comunitaria y cósmica porque se halla inserto y fundido en ella. Bajo esta concepción, el cuerpo humano es intocable e inviolable y, justamente por ello, su interior es invisible. En el mundo medieval, signado por la trascendencia cristiana y las tradiciones populares, "el hombre (inseparable del cuerpo) es una cifra del cosmos, y hacer correr la sangre, aun cuando sea para curar, es lo mismo que romper la alianza y trasgredir el tabú" (Le Breton, 2002, p. 38 el subrayado es mío). En la Modernidad, la ruptura de la alianza por la cual se establecía la identidad de mundohombre-cuerpo conlleva consecuencias centrales para el campo de la práctica médica y, correlativamente, para los cambios de paradigmas de la salud y para el desarrollo de los procesos de medicalización. Precisamente, Le Breton explica que la medicina moderna nace de esta fractura ontológica que habilita la producción de imágenes del cuerpo humano a partir de las representaciones anatómicas de los cuerpos sin vida.

Ya en el siglo XVI comienzan a prefigurarse las representaciones de la concepción moderna del cuerpo que mantiene su vigencia en la actualidad. La definición moderna del cuerpo tiene origen en una múltiple diferenciación: el hombre se distingue y aparta del cosmos, de los otros hombres y de sí mismo, tres esferas que se hallaba íntimamente ligadas. Esta separación abre la posibilidad de la apropiación del cuerpo tanto por parte del individuo que lo posee como por parte de otros ${ }^{3}$. Es así que a partir de la ruptura con su trama comunitaria y cósmica, el individuo comienza a poseer un cuerpo puesto que ya no se encuentra identificado con él: deja de habitarlo para poseerlo, y como fruto de esa separación, el cuerpo emerge como un residuo ${ }^{4}$.

3 Ahora bien, además de separarse de su cuerpo, el hombre se separa del tiempo-espacio al que estaba integrado. Por ello, en términos de corolario de aquella ruptura, puede pensarse que también se abre la posibilidad de la apropiación del espacio y del tiempo. En este sentido, el espacio apropiado se convierte en paisaje que puede ser diseñado en pos de comodidades para la vida del hombre. Por su parte, el tiempo es descompuesto en unidades de tiempo menores para poder apropiar cada instante de la vida, cuyo transcurso el reloj se esfuerza en recordar en cada segundo.

4 El cuerpo como posesión del hombre también puede ser entendido a partir del planteo de Paul Valery en torno a la distinción (en el ámbito del pensamiento) de tres cuerpos. El primero de esos tres cuerpos es 
De esta manera, el hombre es convertido en individuo, y el cuerpo es inventado como tal5.

El cuerpo es considerado el factor de individuación que marca el lugar de un límite: la frontera entre un individuo y otro. Le Breton concibe al cuerpo como el "índice de una ruptura entre el hombre y el cosmos" (2002, p. 47); como la cicatriz de una indiferenciación con el mundo perdida o rota, o la huella de una comunión que se espera volver a encontrar. En tanto el cuerpo es el lugar de ruptura, expone Le Breton, "se le otorga el privilegio de la reconciliación. Es ahí donde hay que aplicar el bálsamo" (2002, p. 170 el subrayado es mío). Esta expresión hace pensar en un calmante, un paliativo o un medicamento que debe ser aplicado sobre el cuerpo para aliviar la llaga de aquella ruptura o la cicatriz que no es otra cosa que el mismo cuerpo. Esta perspectiva no puede dejar de llamar la atención al tratarse, aquí, de una revisión de la relación entre la utopía de la salud perfecta y los procesos de medicalización.

Por otra parte, la filosofía mecanicista desarrollada en el siglo XVII en Occidente también influye sobre los procesos que habían dado lugar a la nueva concepción del cuerpo. La inteligibilidad mecanicista no concibe que haya nada que no sea reductible al mecanismo, y así tampoco el cuerpo del hombre. La concepción del cuerpo-máquina no es contradictoria con la del cuerpo objetivado y racional de la Modernidad, sino mutuamente subsidiarias. De esta manera, el cuerpo objeto es "un cuerpo fraccionado de acuerdo con un esquema mecanicista y reconstruido a través de un proceso de control" (Le Breton, 2002, p. 231). El cuerpo concebido en la Modernidad es, entonces, un cuerpo objetivado, racional y mecánico.

La mutación ontológica de la concepción del cuerpo tiene importantes implicancias epistemológicas y metodológicas. El cuerpo objetivado permite ser convertido en objeto de estudio y con ello se abre la posibilidad de que sea interrogado científicamente ${ }^{6}$. Así también, la medicina interviene sobre el cuerpo sin que eso implique ya ningún tipo de transgresión: "El cuerpo humano, desde la concepción hasta la muerte (e incluso post

ese objeto identificado como Mi-Cuerpo, del que se habla a terceros "como de una cosa que nos pertenece" (Valery, 1998, p. 84).

5 En el planteo de Le Breton, la invención del cuerpo es la primera etapa de los procesos de individuación de las sociedades occidentales. Paralelamente al ascenso del individualismo, se debilitan los lazos entre los sujetos, y el cuerpo se convierte en objeto de exhibición; de ahí que en el segundo momento de estos procesos tenga lugar la emergencia de una sensibilidad narcisista. Desde el punto de vista que expone Paul Valery en "El problema de los tres cuerpos", este cuerpo inventado, narcisista y exhibido se corresponde con el segundo: el que tiene una forma para los demás, el que ven los otros y se ofrece en los espejos (Cfr. Valery, 1998).

6 A partir de la posibilidad de intervención científica sobre el cuerpo, la nueva mirada metodológica -según objeta Le Breton- es una mirada que olvida al hombre para considerar solo el cuerpo. Alineado a los comentarios realizados en dos notas anteriores, puede considerarse que este cuerpo interrogado científicamente corresponde al Tercer Cuerpo del esquema de tres cuerpos propuesto por Paul Valery: el que para los científicos no es sino fragmentos, que "no tiene unidad más que en nuestro pensamiento, puesto que no se le conoce más que por haber sido escindido y partido en pedazos" (Valery, 1998, p. 88). 
mórtem) está controlado por la medicina", dice Le Breton (2002, p. 228). Pero no solo es la medicina la que demanda al cuerpo para su observación y control. También

... el cuerpo (...) vuelve a situarse en el centro de la escena, exige cuidados, una atención sostenida, se ofrece como sujeto y como objeto. Escaneado, auscultado hasta sus últimos pliegues, reemplazado por pedazos, trasplantado en todo sentido, con la promesa de supervivencia para sus órganos, el cuerpo humano es fuente y foco de investigaciones tecnocientíficas y paracientíficas (Sfez, 2008, p. 53).

A la luz de la metáfora del cuerpo-máquina heredada y de la utopía de la salud perfecta de radical vigencia en las sociedades del siglo XXI, la práctica de intervención corporal debe ser asociada con dos nociones centrales, distintas pero conectadas como tendidas en medio de una vía de doble circulación. Por un lado, la idea de intervención remite a la de reparación: "Curiosamente -observa Le Breton- el paradigma del cuerpo confiable y lleno de vitalidad es el de la máquina bien mantenida" (2002, p. 160); es decir, que existe y debe existir una voluntad de mantener, controlar, modificar y corregir el cuerpo para que este sea intervenido. Al mismo tiempo esto presupone la noción y concepción de cuerpos intercambiables (Virilio, 1999, p. 39), sin la cual ninguna intervención, modificación y corrección del cuerpo sería posible.

Bajo esta concepción, Le Breton observa que el cuerpo humano "se convierte en un laboratorio donde se realizan las intervenciones para acoplar organismo y máquina" (2002, p. 245). Esto mismo también es subrayado por Donna Haraway al sostener que "la medicina moderna está asimismo llena de cyborgs, de acoplamientos entre organismos y máquinas" (1995, p. 253)7. El hablar de acoples orgánico-maquínicos hace pensar en un cuerpo fragmentado en partes intercambiables que pueden ser remplazadas por piezas para su modificación o mejor funcionamiento. El cuerpo ya no es el organismo que debe ser atendido y cuidado como una máquina, sino que es un cuerpo suplementado por la máquina. El artificio tecnológico que se implanta en el cuerpo le permite -al hombre que lo posee- restaurarse, completarse, perfeccionarse y embellecerse. Resulta necesario reparar en que "el hombre con una prótesis es una especie de rehén de la máquina y de los que conocen su funcionamiento" (Le Breton, 2002, p. 247). Ese es el hombre cuyo cuerpo exige cuidados y demanda atención descrito por Sfez párrafos más arriba.

Este cuerpo que permite ser acoplado y transformado es el nuevo modelo de cuerpoborrador (Le Breton, 2002), en el que se combinan los supuestos del cuerpo tecnológico (Haraway, 1995) y el paradigma del cuerpo como campo de modelación (Ferrer, 2004). Esta concepción de cuerpo encuentra su origen en la década del sesenta del siglo XX, cuando tiene lugar una enorme perturbación de las claves sociales y culturales mantenidas hasta el momento (Ferrer, 2004; Le Breton, 2002). A partir de allí, se configura una ideología que postula el ideal de cuerpo bello y joven; y el cuerpo comienza a ser valorado como un objeto estético. Como consecuencia de esta ideología, y para satisfacer las demandas

7 Donna Haraway hace referencia a los acoplamientos entre organismo y máquina en estos términos debido a que concibe que los cyborg son un "organismo cibernético, un híbrido de máquina y organismo, una criatura de realidad social y de ficción (...) que viven en mundos ambiguamente naturales y artificiales" (1995, p. 253). Además, afirma que la de cyborg es la ontología del hombre de finales del siglo XX. 
que la revolución cultural había generado, se ha desplegado un conjunto de industrias y técnicas dirigidas a la amortiguación del cuerpo y el cuidado de la salud como la cosmética, la gimnástica, la psicofarmacéutica, la dietética, la dermatología, la plástica, etcétera. Sin embargo, estas industrias terminaron siendo compensadoras frente a la imposibilidad de alcanzar un modelo ideal de cuerpo y salud (Ferrer, 2004).

La cultura de una época instaló los cimientos para la apropiación científica del cuerpo (Gómez, 2009; Le Breton, 2002). La medicina en general, sus diversas especialidades en particular, y las variadas tecnologías e industrias desarrolladas en torno al campo médi$\mathrm{co}$, se valen necesariamente del paradigma de cuerpo perfilado en la Modernidad para ejercer y extender su práctica. De otro modo, ¿̇cuál sería la historia de la medicalización si la historia del cuerpo hubiera sido otra? La objetivación del cuerpo es condición para la intervención y su manipulación médico-tecnológica, ya sea a los fines de su asistencia o de su alteración plástica o genética.

El paradigma del cuerpo tecnológico en el que la tecnología penetra el cuerpo para refinar su funcionamiento y el paradigma de la plástica en el que el cuerpo es moldeado, modelado o esculpido de acuerdo con necesidades o deseos humanos son dos caras de la misma moneda. Caiga cara o caiga sello, el cuerpo será objeto de un sinfín de prácticas, experimentaciones y consumos por los cuales se busca su perfectibilidad. El cuerpo es la base material de la que habla Sfez, en la que ancla el sentido de la utopía de la salud perfecta. Un extenso conjunto de prácticas, técnicas, expresiones y metáforas vigentes en la actualidad -y de total incumbencia al campo problemático que aquí se aborda- son deudoras de la concepción moderna del cuerpo.

No obstante, en la medida en que Sfez postula al cuerpo como la base material de un nuevo sentido sobre el que se funda la utopía de la salud perfecta, es evidente que no se refiere a aquella misma concepción de raíz moderna. Esta concepción ha variado progresivamente en tanto las prácticas sobre el cuerpo también fueron modificándose: aggiornamiento epistemológico a las nuevas prácticas sociales y a las innovaciones tecnológicas que encuentran en el cuerpo como su objeto y medio privilegiado de expresión.

\section{Resultados de la investigación}

La estrategia metodológica diseñada permitió articular los fenómenos de medicalización y de salud perfecta a través del análisis del discurso publicitario de la industria farmacéutica, por el que fue posible reconocer las significaciones que configuran los principales núcleos de sentido de tales fenómenos. Mediante el análisis del discurso audiovisual del corpus de cincuenta spots publicitarios referentes a productos médicos y cosméticos se ha logrado reconocer y reconstruir el sistema significante del imperativo de salud perfecta que opera en el discurso de la industria farmacéutica como un dispositivo para la invención de enfermedades y la medicalización de la vida cotidiana.

Aquí se sistematizan los resultados del análisis de las significaciones relativas a la noción de cuerpo, salud y enfermedad a partir de cuatro grandes núcleos semánticos: (a) 
la violación de la propiedad corporal privada, (b) el cuerpo desconocido, (c) la figura del enemigo interno y (d) el control y la protección corporal.

\section{(a) La violación de la propiedad corporal privada}

Una de las imágenes a destacar sobre la representación del cuerpo en relación con la salud y la enfermedad en los discursos publicitarios de la industria farmacéutica analizados es la del cuerpo como una propiedad corporal privada que debe ser protegida y puede resultar violada, vulnerada o invadida por virus, bacterias, gérmenes y agentes portadores de un malestar que asume distintas formas y se hallan difuminados en el propio ambiente.

Con respecto a la invasión corporal por parte de distintos tipos de agentes portadores de malestar se ha diferenciado tanto causas de dolor localizadas al interior del cuerpo (garganta, estómago, circulación sanguínea), como provenientes del exterior (elementos de peso que provocan dolor muscular, bacterias, factores del ambiente como el sol, etcétera); ambas, igualmente objeto de operaciones discursivas de hiperbolización de la imagen de malestar y dolor.

Estas imágenes resultan igualmente válidas para todas las variantes del mecanismo de invención de enfermedades analizadas debido a que el malestar se presenta siempre como una amenaza inminente y absoluta. Asimismo, en todos los casos analizados, el malestar o las causas adjudicadas a su sensación son representados como algo monstruoso que impide, interrumpe $\mathrm{o}$, al menos, dificulta la continuidad de las tareas u obligaciones cotidianas.

\section{(b) El cuerpo desconocido}

El sentido de amenaza que representan los distintos factores que causan el malestar, se corresponde con otra imagen de cuerpo por la que este es representado como un territorio desconocido. Es ese desconocimiento del cuerpo el que lo torna vulnerable ante las amenazas y riesgos de malestar. A los fines analíticos, esta significación de cuerpo desconocido puede ser presentada a partir de otras dos imágenes: la imagen de lo invisible y la imagen de lo extraño.

La imagen de lo invisible del propio cuerpo es construida, a su vez, por medio del enlace de dos imágenes complementarias. Por un lado, las imágenes de lo interior remiten a las representaciones del interior del cuerpo humano que resultaron ser una regularidad significante en el discurso de los laboratorios. Mediante esquemas digitales y animaciones tridimensionales se muestra la obstrucción de las vías respiratorias en un cuadro de tos, la virulencia de las enzimas estomacales a causa de la acidez frecuente, la exacta localización de los dolores musculares, la dilatación de las venas que causan problemas de circulación sanguínea, etcétera. Mediante este tipo de imágenes se hace referencia al nivel en el que actúan los productos publicitados o, mejor dicho, estas imágenes son metáforas visuales de la profundidad de su acción.

Por otro lado, también resultaron frecuentes las imágenes de lo micro o microscópico. Los gérmenes invisibles de amplia propagación son detectados mediante lentes de 
aumento metafóricamente proporcionadas por los departamentos de investigación de los laboratorios. Lo mismo ocurre con el desprendimiento de células del cuero cabelludo ante la resequedad capilar, la descamación de las hebras del cabello a causa del maltrato infligido, las marcas en los dientes que favorecen la acumulación de bacterias y aparición de manchas, la restauración de las fibras de colágeno en la dermis del rostro y la consecuente recuperación de la firmeza y elasticidad, etcétera. Todos estos procesos microscópicos son expuestos y vueltos visibles a través de la mirada de la investigación tecnocientífica.

De esta manera, las imágenes de lo interior y lo micro resultan complementarias en el discurso de los laboratorios para la construcción de una imagen de un cuerpo del que no se tiene pleno conocimiento porque es presentado como un adentro corporal invisible. El cambio de escala operado en estas imágenes genera un sentido de distancia, por lo que el interior del cuerpo es presentado como un territorio lejano, de acceso dificultoso o facilitado solo por medio de la intervención médica. Por lo tanto, el cuerpo resulta desconocido, así como también son desconocidos los procesos que ocurren en él. La auto-percepción de ese desconocimiento impulsa expresiones y búsquedas de control y protección del cuerpo, frente a diversos factores extraños que pueden invadirlo, vulnerarlo o conquistarlo.

La segunda de las imágenes por las que es construida la significación de cuerpo desconocido es la imagen de lo extraño o, más precisamente, la representación del propio cuerpo como un cuerpo extraño. Los múltiples tipos de elementos extraños que se condensan en este sentido pueden ser presentados en tres grupos. El primero de estos está formado por componentes internos al propio cuerpo (procesos orgánicos como la circulación sanguínea, la digestión, el funcionamiento intestinal, la sensación de dolor), vueltos extraños debido a la invisibilidad, la distancia y el desconocimiento del propio cuerpo. El segundo grupo de elementos extraños comprende a los agentes externos que invaden el cuerpo, ya sea por voluntad o acción humana (como el cigarrillo o la tintura y el secador aplicados sobre el cabello) o por factores que el sujeto no controla (como los virus, las bacterias, los gérmenes, los hongos) que causan malestar o dolor. Y el tercer grupo está compuesto por elementos extraños in-corporados correspondientes a productos médico-cosméticos, en principio no patógenos, interiorizados para desvanecer la acción de los elementos del segundo grupo, y para controlar y armonizar los efectos que estos últimos producen sobre los elementos del primero.

\section{(c) La figura del enemigo interno}

El carácter interno del enemigo de la utopía de la salud perfecta en el siglo XXI y el anclaje corporal del nuevo sentido en que esta se sustenta constituyen dos núcleos teóricos principales de la utopía de la salud perfecta (Sfez, 2008). A trasluz del análisis efectuado en la investigación empírica es posible analizar la figura del enemigo interno característico de la utopía tecnológica de la salud perfecta a partir del conjunto de agentes "extraños" y "monstruosos" que invaden o vulneran el cuerpo. Vale señalar que, aunque algunos agentes portadores del malestar fueran identificados como provenientes del exterior, la 
vía de su in-corporación y su percepción interna constituye un mecanismo que permite comprender precisamente el carácter "interno" de los mismos.

La diversidad de manifestaciones que asumen el dolor, el malestar y el displacer posibilita la expansión del campo de sentido correspondiente al polo de lo radicalmente "otro" que siempre es peligroso, amenazante, diabólico, oscuro o secreto, encarnado en el enemigo interno de la utopía de la salud perfecta. El análisis efectuado permitió reconocer estos factores heterogéneos de peligro constante en relación con las cinco variantes en que se presenta el mecanismo de invención de enfermedades en los procesos contemporáneos de medicalización (Blech, 2005; Rodríguez Díaz, 2008). En la variante de invención de enfermedades a partir de procesos de la vida, el enemigo interno es identificado con marcas corporales en rostro, piel o cabello que representan una pérdida o degradación de la salud y la vitalidad a causa del envejecimiento, o bien un signo de corrupción e imperfección a causa de la fealdad. En la segunda variante correspondiente a invención de enfermedades a partir de problemas personales o sociales, el enemigo a combatir es encarnado en el mal humor y la inestabilidad emocional ante la necesidad de mantener el ritmo exigido por la vida cotidiana. En tercer lugar, en la variante de invención de enfermedades a partir de factores de riesgos, el modo en que es representada la amenaza presente del enemigo interno radica en la infelicidad y la preocupación ante el riesgo de contraer un mal mayor en un futuro incierto, pero aparentemente inminente. En la cuarta variante relativa a síntomas poco frecuentes, tales como las disfunciones sexuales, la imposibilidad de gozar plenamente del cuerpo propio y del otro son los factores que constituyen paradójicamente esa alteridad maligna que debe ser combatida. Finalmente, en la quinta variante de invención de enfermedades a partir de síntomas leves, el enemigo interno o internalizado es identificado con diversos agentes y sensaciones que irrumpen en el cuerpo y dificultan el desempeño cotidiano de la vida, como la gripe, el dolor muscular, el cansancio, etcétera.

En todos los casos, el enemigo interno busca ser controlado y combatido para alcanzar la perfección de la salud y del cuerpo; como un antagonismo que amenaza con subvertir el orden del sistema pero que, a su vez, le otorga estabilidad en tanto los componentes internos adquieren sentido en pos de la negación y el rechazo de dicho antagonismo (Laclau y Mouffe, 1987). En ninguno de los casos existe posibilidad de articulación, integración, consentimiento, concesión, distracción o descuido: el malestar es heterogéneo y absoluto, y su exclusión es radical. En este sentido, la generalización de la salud en la utopía de la salud perfecta es, entonces, consecuencia de la exclusión radical de las diversas formas de malestar por medio de la intervención médico-cosmética posibilitada tecnológicamente.

\section{(d) El control y la protección corporal}

La significación de control corporal interesa particularmente en tanto atañe, en términos de Sfez (2008), a la moralidad cotidiana de la utopía de la salud perfecta. El análisis desarrollado revela que la representación del cuerpo como un interior a ser protegido es indisociable de la búsqueda de control corporal como medio para alcanzar la perfección de la salud y del cuerpo. 
Las significaciones de control y protección del cuerpo se hallan presente en todas las variantes del mecanismo de invención de enfermedades analizadas, aunque asumen distintos sentidos, formas y finalidades. En la variante de invención de enfermedades a partir de procesos de la vida, el control busca ser ejercido sobre el paso del tiempo y las marcas que este deja sobre el cuerpo, para la protección y la recuperación de su plenitud. En la variante problemas personales o sociales, la búsqueda de control recae sobre los humores y estados de ánimo que comportan, según se advierte, un perjuicio para la salud. En la variante factores de riesgo se promueve el control de circunstancias, factores y hábitos del presente con el fin de evitar ciertos estados representados como riesgos en el futuro. En el abordaje de la variante síntomas poco frecuentes, el control está centrado sobre las sensaciones corporales en busca de mayor placer. Y en la variante síntomas leves, el control de las sensaciones de malestar y dolor obedece al imperativo de continuar el ritmo de la vida cotidiana.

Sin embargo, la búsqueda de control ante el desconocimiento del propio cuerpo y los factores que lo atacan contrasta con otro sentido que el discurso publicitario de los laboratorios farmacéuticos busca estabilizar para todas las variantes del mecanismo de invención de enfermedades analizadas. La representación de la relación con el propio cuerpo se emparienta más con un sentido de cuerpo vivido, sentido o apropiado para ser disfrutado íntegra, libre y plenamente que con una relación explícita de control consciente, omnímodo o directo. No obstante, esa imagen de cuerpo ofrecida y propiciada por el discurso publicitario de la industria farmacéutica es viabilizada por el uso-consumo de modo regular y adictivo de una vasta gama de productos médico-cosméticos comercializados. De allí que el control y conocimiento del propio cuerpo, representado justamente como desconocido-distante-inaccesible, queda exclusivamente en manos de los laboratorios farmacéuticos y cosméticos.

\section{Conclusiones}

Con base en las observaciones efectuadas en el análisis y recordando los postulados de Sfez en torno al nuevo sentido que ancla en el cuerpo como base material de la utopía de la salud perfecta, es posible señalar que este no resulta tan novedoso si se reconoce que su fundamento se halla en el imaginario moderno que permitió la objetivación del cuerpo y su intervención. Sin embargo, a diferencia de la visibilidad externa e interna que gana el cuerpo a partir de su separación del hombre a comienzos del siglo XVI, los discursos publicitarios del siglo XXI continúan apelando a la invisibilidad corporal como justificación de la necesidad del llamado a la intervención tecnológica y médica para lograr su visibilidad, conocimiento y control. De esta manera, los sentidos de invisibilidad, interioridad y desconocimiento parecieran contrastar con el sentido de transparencia del cuerpo individual a la que aspira la utopía de la salud perfecta o la Gran Salud para poder vigilar y controlar todo.

No obstante, cabe observar que la recurrente tematización de las esferas corporales interior y exterior permite construir la significación de cuerpo reversible: un cuerpo que debe ser cuidado, controlado y protegido de ambos lados, interna y externamente. La reversibilidad 
corporal construida por el discurso publicitario de la industria farmacéutica para la invención de enfermedades puede ser explícitamente articulada con la transparencia a la que aspira la Gran Salud de la utopía de la salud perfecta. De esta manera, la apelación a "protegerse por dentro y por fuera", la referencia al "efecto de penetración" de las sustancias médicas o cosméticas y a la acción de estos productos que brindan un "cuidado de adentro hacia afuera", mencionadas en los spots, sitúan el campo de combate del enemigo en el interior del cuerpo. Al mismo tiempo, configuran un sentido de búsqueda y necesidad de cuidadoprotección-control que, leído en relación con las imágenes de cuerpo desconocido, interior y extraño, genera el efecto de conocimiento y control fármaco-cosmético de los procesos corporales y, de esta manera, también su visibilidad-transparencia.

Por otra parte, corresponde señalar que esa búsqueda de control corporal es soslayada por un discurso que, contrariamente, promueve la búsqueda de disfrutegoce-placer-distensión-relajación-tranquilidad-placidez-armonía-bienestar en pos de la confianza otorgada a la eficacia de los productos fármaco-cosméticos desarrollados con tal propósito. Esta observación podría hacer pensar que las afirmaciones de Sfez relativas a la moralidad cotidiana de control corporal de la utopía de la salud perfecta no resultan regularidades significantes en los discursos referentes al cuidado de la salud y del cuerpo. Sin embargo, corresponde notar que precisamente el discurso publicitario que insta y promueve el disfrute-bienestar y disimula el control actúa como un dispositivo ideológico de control corporal. Por lo tanto, mediante el análisis de los discursos publicitarios se advierte no solo que las afirmaciones de Sfez resultan corroboradas como dimensiones de análisis fecundas, sino que también es posible identificar el mecanismo por el que se establece la moralidad cotidiana de control corporal y la forma en que esta se despliega.

Desde este punto de vista, el discurso de la industria farmacéutica referente al cuidado de la salud y del cuerpo actúa como un dispositivo que opera en el nivel de los cuerpos y en el ideológico, por medio de un discurso que no requiere hacer explícita la búsqueda de control corporal de manera directa. Su operación consiste en la configuración de un sentido de cuidado y protección del cuerpo y de la salud que, indirectamente, promueve prácticas por medio de las cuales alcanzar el control corporal (tal como el uso-consumo de la gran variedad de productos médico-cosméticos comercializados por la misma industria), para lo cual requiere la producción de subjetividades que se asuman como corporalidades enfermas. En este sentido, la instalación social de la preocupación por la expansión y amenaza de enfermedades, malestares, riesgos y por la vulnerabilidad e imperfección del cuerpo, así como la instalación de la necesidad de uso-consumo de los productos para la protección corporal, contribuyen a la consolidación de un modelo de salud perfecta-medicalizada, que no es otro sino el que irriga al paradigma de la salud del siglo XXI. 


\section{Bibliografía}

Arroba, A. (2003). La medicalización de los cuerpos de las mujeres en la era de la globalización. Revista Mujer Salud. Red Salud de Mujeres Latinoamericanas y del Caribe, enero, 3-11.

Blech, J. (2005). Los inventores de enfermedades. Cómo nos convierten en pacientes. Barcelona: Destino.

Cabral Barros, J. A. (2008). Nuevas tendencias de la medicalización. Ciência y Saúde Coletiva, 13, 579-587.

Conrad, P. (1982). Sobre la medicalización de la anormalidad y el control social. Psiquiatría clínica. La política de la salud mental. Barcelona: Crítica-Grjalbo.

Conrad, P. (2007). The medicalization of society. On the Transformation of Human Conditions into Treatable Disorders. Baltimore: The Johns Hopkins University Press.

Costa, F. y Rodríguez, P. (2010). La vida como información, el cuerpo como señal de ajuste: los deslizamientos del biopoder en el marco de la gubernamentalidad neoliberal. En V. Lemm (Ed.), Michel Foucault: biopolítica y neoliberalismo. Santiago de Chile: Editorial Universidad Diego Portales.

Chodoff, P. (2002). The medicalization of the Human Condition. Psychiatric Services. American Psychiatric Association, 53(5), 627-628.

Díaz Rojo, J. (2002). La belleza es salud. La medicalización lingüística de la publicidad de los cosméticos. Contextos(XIX-XX/37-40), 109-112.

Epele, M. (2010). Usos y abusos de la medicalización en el consumo de drogas. En A. C. y. E. Luchtenberg (Ed.), Medicalización y sociedad. Lecturas críticas sobre la construcción social de enfermedades (pp. 79-100). Buenos Aires: UNSAM Edita.

Ferrer, C. (2004). El arte del cuerpo en la era de su infinita perfectibilidad técnica Recuperado el 5 de julio, 2012. Disponible en: http://www.liminar.com.ar/txt/ferrer.pdf

Foucault, M. (1996a). Historia de la medicalización. En M. Foucault (Ed.), La vida de los hombres infames (pp. 85-105). Buenos Aires: Altamira.

Foucault, M. (1996b). La crisis de la medicina o la crisis de la antimedicina. En M. Foucault (Ed.), La vida de los hombres infames (pp. 67 84). Buenos Aires: Altamira.

García-Arnaiz, M. (2007). Comer mal, comer bien: la medicalización del comportamiento alimentario. Salud pública de México, 49(3), 236-242.

Gómez, D. (2009). Medicina y subjetividad: la apropiación del hombre por parte de la medicina moderna. Una lectura desde los textos de Michel Foucault. Abraxas Magazine. Psicología, sociedad, cultura, 2, 8-10.

Haraway, D. (1995). Manifiesto para cyborgs: ciencia, tecnología y feminismo socialista a finales del siglo XX. En D. Haraway (Ed.), Ciencia, cyborgs y mujeres. La reinvención de la naturaleza (pp. 251-311). Madrid: Cátedra.

Lacan, J. (2003). La instancia de la letra en el inconsciente o la razón desde Freud. En J. Lacan (Ed.), Escritos I (pp. 473-309). Buenos Aires: Siglo XXI.

Laclau, E. y Mouffe, C. (1987). Hegemonía y estrategia socialista. Hacia una radicalización de la democracia. Buenos Aires: Fondo de Cultura Económica.

Le Breton, D. (2002). Antropología del cuerpo y modernidad. Buenos Aires: Nueva Visión.

Lupton, D. (1997). The Imperative of Health: Public Health and the Regulated Body. Londres: Sage. 
Montse, J. (1991). Crear el nacimiento: la medicalización de los conflictos en la reproducción. REIS: Revista Española de Investigaciones Sociológicas(53), 29-51.

Moral Jiménez, M. d. 1. V. (2008). Crítica a la visión dominante de salud-enfermedad. Patologización preventiva de la vida cotidiana. Boletín de Psicología(94), 85-104.

Moyniham, R., Heath, I. y Henry, D. (2002). Selling sickness: the pharmaceutical industry and disease mongering. British Medical Journal, 234(7342), 886-891.

Muel, F. (1991). La escuela obligatoria y la invención de la infancia anormal. Espacios de Poder. Madrid: La Piqueta.

Rodríguez Díaz, S. (2008). El proceso de medicalización y sus consecuencias. Entre la moral, el poder y el negocio. Intersticios: Revista Sociológica del pensamiento crítico, 2(2).

Rodríguez Zoya, P. (2011). Medicalización y salud perfecta: La doble cara del nuevo paradigma de la salud. Análisis del discurso de la industria farmacéutica a través de spots publicitarios de productos de venta libre, (2009). Tesis de Licenciatura en Ciencias de la Comunicación, Facultad de Ciencias Sociales, Universidad de Buenos Aires, Argentina.

Salvarezza, L. (2001). El envejecimiento. Psiquis, poder y tiempo. Buenos Aires: Eudeba.

Sfez, L. (2008). La salud perfecta. Crítica de una nueva utopía. Buenos Aires: Prometeo.

Smith, R. (2002). In search of 'non-disease'. British Medical Journal, 324(7342), 883-885.

Valery, P. (1998). El problema de los tres cuerpos. En Discurso a los cirujanos. México: Universidad Autónoma Metropolitana.

Virilio, P. (1999). La bomba informática. Madrid: Cátedra. 